\title{
Analysis of Effect of Thermal Barrier Coating Materials on Efficiency of IC Engines Using 3D Finite Element Method
}

\author{
Durga Raghu Ram Pendyala ${ }^{1}$, Kaarthik V.M ${ }^{2}$, Puviyarasan $\mathrm{M}^{3}$ \\ ${ }_{1,2}$ (Dept. of Mechanical Engineering, Panimalar Engineering College, India) \\ 3 (Associate Professor, Dept. of Mechanical Engineering, Panimalar Engineering College, India)
}

\begin{abstract}
The paper proposes the use of Thermal Barrier Coating (TBC) materials in IC Engines to improve their thermal efficiency. Firstly, thermal analyses are investigated on two conventional (uncoated) single cylinder Petrol Engine models, made of Grey Cast Iron (GRADE ASTM 40) and aluminum silicon alloy. Secondly, thermal analyses are performed on two different specially designed petrol engine models, each of its combustion chambers being coated with two different Thermal Barrier Coating materials namely Perovskite Type Strontium Zirconate and Ruddlesden-Popper structured Barium Lanthanum Titanate BaLn2Ti3O10(BLT); by means of using a commercial code called ANSYS. Finally, the results obtained from all four thermal simulations are compared with each other. The effects of coatings on the efficiency of engines are investigated. Further investigations on these results reveal that there is a considerable reduction in heat loss through combustion chamber when TBCs are used. According to Otto cycle, for an ideal petrol engine the expansion process ought to take place under isentropic conditions (No heat transfer). Engines coated with TBCs restrict heat losses to a maximum extent thereby allowing expansion process to occur in near isentropic conditions. This in turn increases the net available energy. Therefore a raise in thermal efficiency of the engine can be achieved. 3(Associate Professor, Dept. of Mechanical Engineering, Panimalar Engineering College, India)
\end{abstract}

Keywords: Thermal Barrier Coatings (TBC), Perovskite Type Strontium Zirconate, Ruddlesden-Popper structured $\mathrm{BaLn}_{2} \mathrm{Ti}_{3} \mathrm{O}_{10}(\mathrm{BLT})$, Otto Cycle.

\section{Introduction}

Internal combustion engines are the integral part of every automotive, we come across in our day-today life. The reliability of IC Engines, especially petrol (gasoline) based; make them the most widely used prime mover in automobiles. However they are having very poor thermal efficiency. IC engines are constantly being modified in order to meet the rising demand for more efficient generation of power. The increasing pollution levels caused due to vehicular emissions also stress the need for intense research. It has been observed that there is an undesirable heat loss of more than $15 \%$ in an IC Engine through its combustion chamber walls and piston. This heat loss can be avoided by making use of TBC materials.

Ceramics have a higher thermal durability than metals; therefore it is usually not necessary to cool them as fast as metals. Low thermal conductivity ceramics can be used to control temperature distribution and heat flow in a structure [9] [3]. Thermal barrier coatings (TBC) provide the potential for higher thermal efficiencies of the engine, improved combustion and reduced emissions. In addition, ceramics show better wear characteristics than conventional materials. Lower heat rejection from the combustion chamber through thermally insulated components causes an increase in available energy that would increase the in-cylinder work and the amount of energy carried by the exhaust gases, which could be also utilized [10] [12].A lot of experimental study has been done to utilize these ceramic properties to improve thermal efficiency by reducing heat losses, and to improve mechanical efficiency by eliminating cooling systems. When cylinder-cooling losses are reduced, more of the heat is delivered to the exhaust system. This effective recovery of energy by exhaust improves the thermal efficiency of low heat rejection engine (LHR). However, installing heat recovery systems needs considerable effort; a lot of changes are necessary in the engine configuration. Even without heat recovery systems, some of the heat is converted to piston work and increases thermal efficiency. Therefore, LHR engines without exhaust heat recovery systems are worth to study [8].

In this article, we propose the use of thermal barrier coating materials in various components of IC Engine which could greatly improve the thermal efficiency and volumetric efficiency of the engine. A lining of TBC is provided throughout the combustion chamber region which includes the cylinder liner, piston, overhead valve block and valves. The effect of various TBCs is studied by creating a CAD Model of prototype engine and the heat transfer across the interface has been analysed using analysis software- ANSYS. The results obtained from the analysis of different TBCs used in the IC Engine Model have been tabulated. Using these results, the thermal and volumetric efficiencies of IC Engine with different TBCs are interpreted. 


\section{Principle of Design}

The schematic ideal Otto cycle of a petrol engine is as shown in figure 1. The area 1-2-3-4-1 represents the work done by engine during one complete cycle.

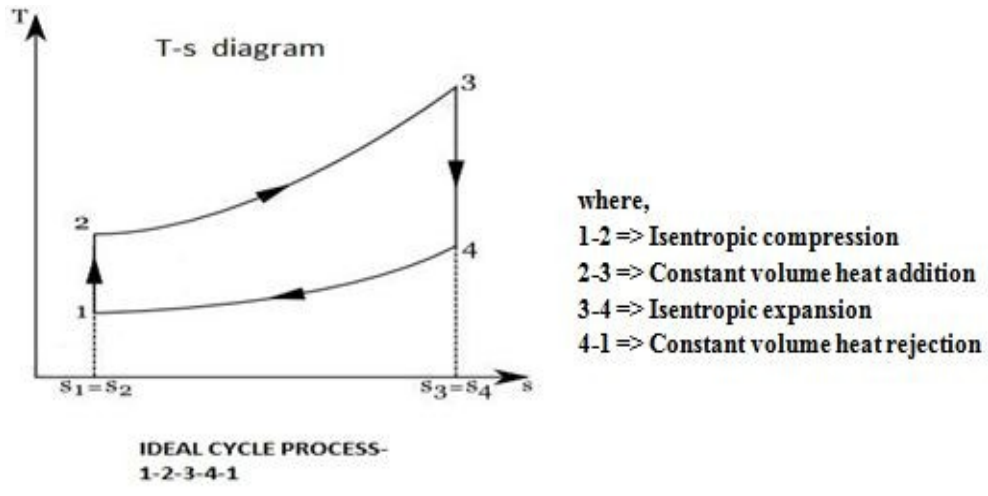

Figure1. Schematic Representation of Ideal Otto cycle TS Diagram

However, in the actual case, the Otto Cycle is as shown in the figure 2(a). It can be seen that due to various reasons, the process 1-2 and 3-4 deviate from the ideal cycle as 1-2' and 3-4 respectively. The net result is decreased work output when compared with ideal cycle, which is represented by the shaded area in figure 2(a). In order to overcome it, we use TBC which make the cycle reject lesser heat through IC engine walls during the process 3-4 (refer process 3-4" in figure 2(b)). Thus the net work output from the IC engine can be increased by increasing its thermal efficiency.

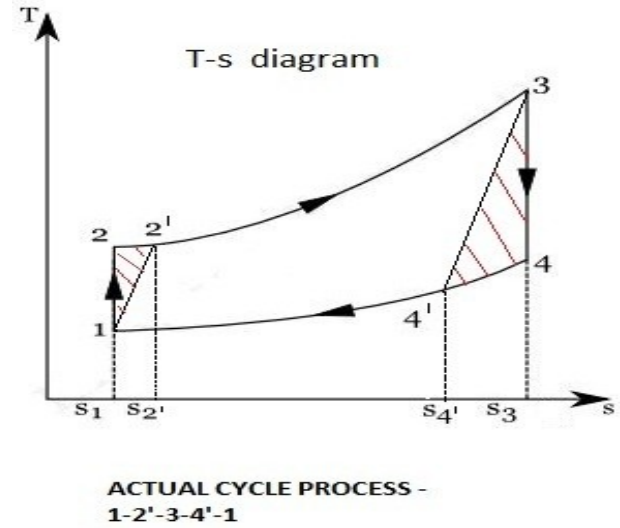

Figure 2(a). Schematic Representation of Actual Otto cycle in Current IC Engine

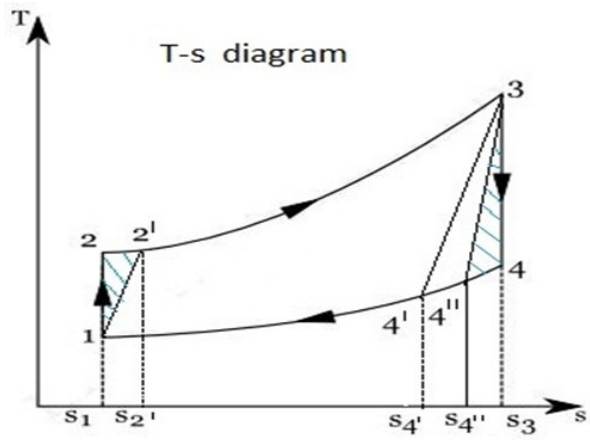

ACTUAL CYCLE WITH TBC -

1-2'-3-4'"-1

Figure 2(b). Schematic Representation of Actual Otto cycle With the Use of TBC in IC Engine

\section{Current Materials For IC Engine}

The most widely used materials for construction of IC Engines are Grey Cast Iron, Aluminium alloys and steels in some parts. Close-grained cast iron is the material most commonly used for liner construction. Some liners are plated on the wearing surface with porous chromium, because chromium has greater wearresistant qualities than other materials [5].

Table 1 Commonly Used Materials for Construction of IC Engines

\begin{tabular}{|c|c|c|c|}
\hline S.No. & PROPERTY & $\begin{array}{c}\text { GREY CAST IRON } \\
\text { ASTM } 40\end{array}$ & $\begin{array}{l}\text { ALUMINIUM SILICON } \\
\text { ALLOY[2][5] }\end{array}$ \\
\hline 1 & Density & $7100 \mathrm{~kg} / \mathrm{m}^{3}$ & $2680 \mathrm{~kg} / \mathrm{m}^{3}$ \\
\hline 2 & Melting point & $2100^{\circ} \mathrm{C}$ & $816^{0} \mathrm{C}$ \\
\hline 3 & Specific heat & $490 \mathrm{~J} / \mathrm{KgK}$ & $960 \mathrm{~J} / \mathrm{KgK}$ \\
\hline 4 & Thermal conductivity & $46 \mathrm{~W} / \mathrm{mK}$ & $151 \mathrm{~W} / \mathrm{mK}$ \\
\hline 5 & Thermal expansion & $10.5 \mu \mathrm{m} / \mathrm{mK}$ & $23.5 \mu \mathrm{m} / \mathrm{mK}$ \\
\hline
\end{tabular}




\section{Proposed TBC Materials For IC Engine}

In seeking potential new TBC materials, it makes sense to explore other refractory materials. However, since there are numerous crystal structures known to the mineralogical and crystal-chemistry communities, and each can be formed from several different elements, there are literally thousands of possible compounds to search [1]. Among the most useful thermal barrier coating materials developed, we intend to use the following two materials based on their properties;

I. $\quad \mathrm{BaLa}_{2} \mathrm{Ti}_{3} \mathrm{O}_{10}$ (BLT) with Ruddlesden-Popper structure

II. Perovskite Type Strontium Zirconate

Table 2. Properties of TBC materials considered

\begin{tabular}{|c|c|c|c|}
\hline S.No. & PROPERTY & $\begin{array}{c}\text { BARIUM LANTHANUM } \\
\text { TITANATE (BLT) [6][4] }\end{array}$ & STRONTIUM ZIRCONATE [11][7] \\
\hline 1 & Thermal conductivity & $0.7 \mathrm{~W} / \mathrm{mK}$ & $4.06 \mathrm{~W} / \mathrm{mK}$ \\
\hline 2 & Phase stable temperature & $1500{ }^{0} \mathrm{C}$ & $1300{ }^{0} \mathrm{C}$ \\
\hline 3 & Melting point & $2919 \mathrm{~K}$ & $2883 \mathrm{~K}$ \\
\hline 4 & Density & $4.26 \mathrm{~g} / \mathrm{cm}^{3}$ & $5.48 \mathrm{~g} / \mathrm{cm}^{3}$ \\
\hline 5 & Thermal expansion & $11.3 \times 10^{-6} \mathrm{~K}^{-1}$ & $9.69 \times 10^{-6} \mathrm{~K}^{-1}$ \\
\hline
\end{tabular}

\section{IC Engine Modeling}

The cut view of actual IC Engine model which has been used for various analysis purposes is shown in Fig4 below. It is a simple single cylinder, double overhead valve petrol engine. The model was created using CATIA V5 modelling software and imported into ANSYS 14.0. The inner walls of the IC Engine i.e.; the combustion chamber walls (represented in light grey) are coated with Thermal Barrier Coatings (TBCs) in case of the unconventional models which we are proposing. This is shown in the cut view of figure 4 (in brighter grey).This IC Engine model is then imported into the ANSYS 14.0 software for thermal analysis. First, the model is meshed to obtain approximately 200,000 Nodes and 50,000 elements in each case of thermal analysis.

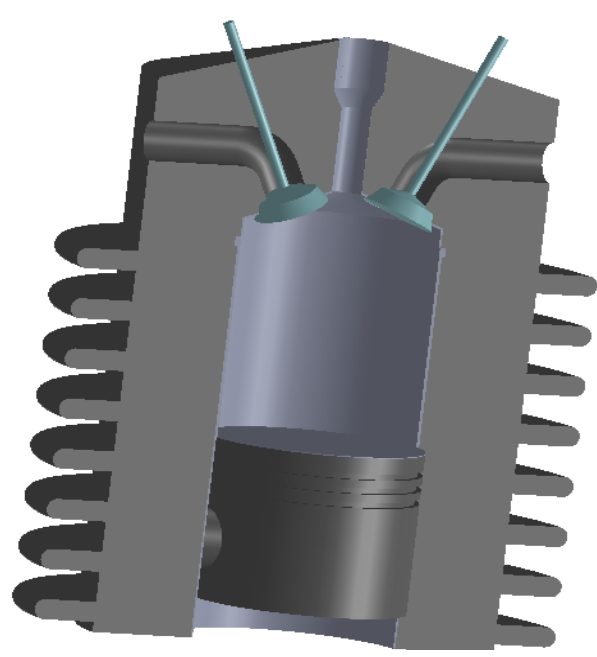

Figure 4. Cut View of Single Cylinder IC Engine Model Created Using CATIA V5

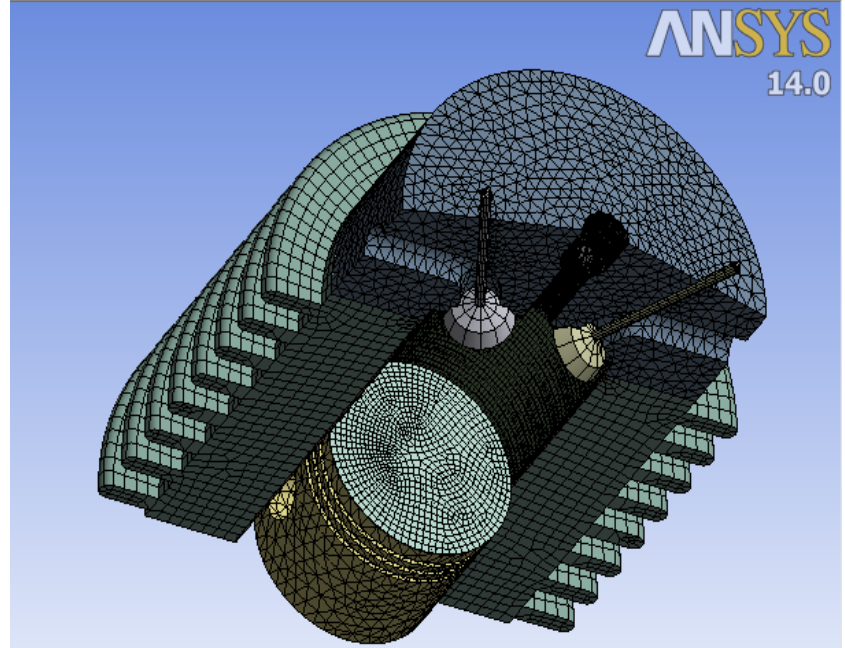

Figure 5. Meshed Model of the IC Engine Using ANSYS 14.0 Software

A comprehensive view of the meshed model of the IC Engine is as shown in the figure 5. The meshed model is then refined to ensure uniform element size throughout the structure of the Internal Combustion Engine and is made ready for thermal analysis simulations.

\section{Assumptions Made In Thermal Analysis By Finite Element Method}

Among the various numerical methods available for mathematical modelling, the Finite Element Method (FEM) has been chosen due to its high degree of accuracy. The following assumptions are made for each of the IC Engine models when performing the thermal analysis on them using ANSYS software.

- The initial temperature of the IC Engine is $373 \mathrm{~K}$.

- The heat flux linked with the walls of IC Engine is $10^{6} \mathrm{~W} / \mathrm{m}^{2}$.

- The average temperature of the IC Engine combustion chamber walls is $1173 \mathrm{~K}$.

- The heat generated due to friction is neglected and the effect of piston motion on the heat transfer is neglected. 


\section{Thermal Analysis Of Conventional IC Engine Models}

Firstly, thermal analysis on uncoated conventional IC Engines is performed in order to visualize the thermal distribution throughout the body. The two materials considered here are Grey Cast Iron (GCI) ASTM GRADE 40 and Aluminum Silicon alloy.

\subsection{THERMAL ANALYSIS ON ALUMINUM SILICON ALLOY ENGINE}

Aluminum Silicon Alloy is the material which is increasingly being used in the construction of modern IC Engines. The entire IC Engine is considered to be made of Aluminum Silicon alloy material except the cylinder liner which is made of Grey Cast Iron (ASTM Grade 40). The thermal analysis is performed for a period of 30 seconds in steps of one second. The state of temperature distribution in the internal combustion engine at the end of 30 seconds is as shown in figure 6 .

\subsection{THERMAL ANALYSIS ON GREY CAST IRON ENGINE}

Another widely used material for the body of internal combustion engine is Grey Cast Iron. In this case, the aluminium Silicon alloy is replaced with Grey Cast Iron completely. Thermal analysis is performed for the same time of 30 seconds and in steps of one second as in the previous case; without changing the mesh quality and test conditions. Figure 7. Represents the heat distribution in the IC Engine body made completely of Grey Cast Iron (ASTM Grade 40) material.

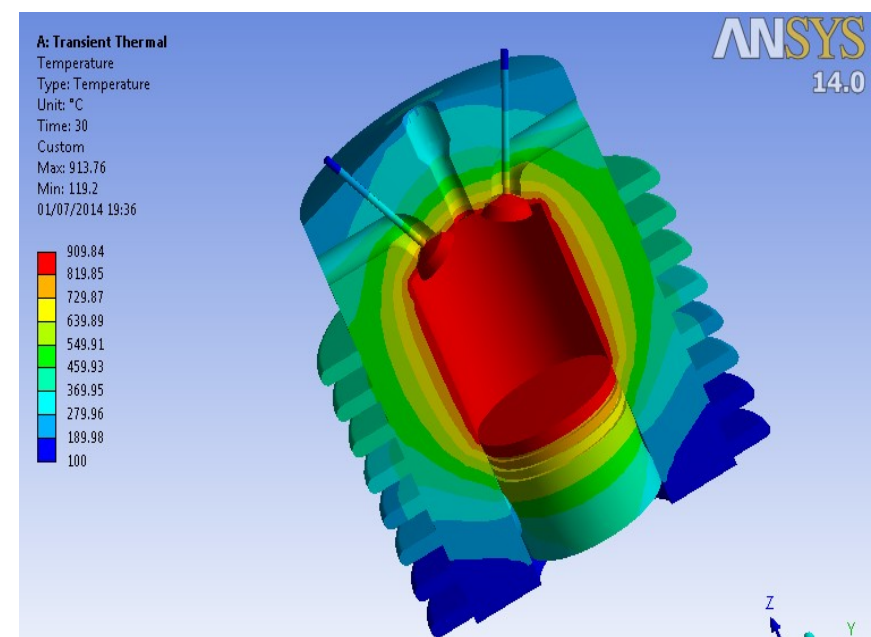

Figure 6. Temperature Distribution In An IC ENGINE Made Of Al Si Alloy

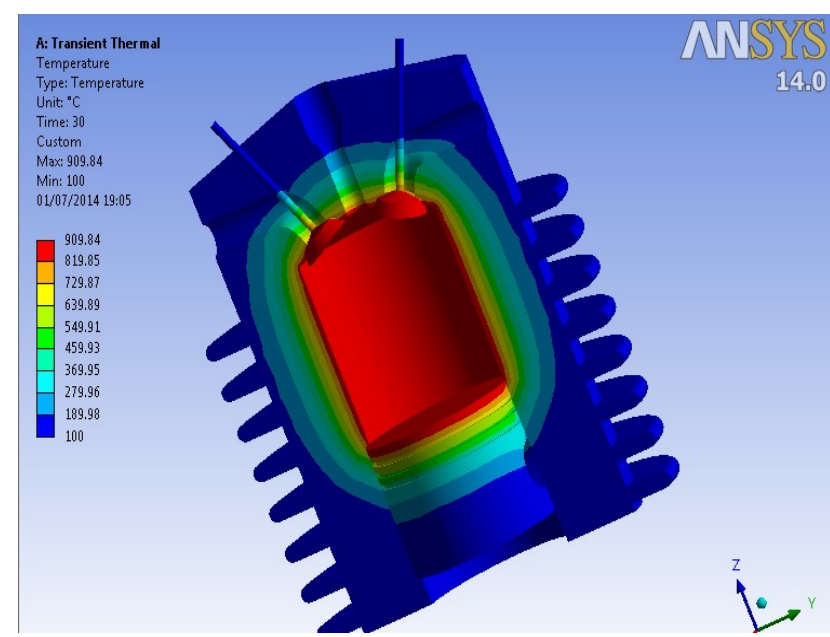

Figure 7. Temperature Distribution In An IC ENGINE Made Of GREY CAST IRON

\section{Thermal Analysis of Proposed IC Engine with TBCs}

Now, thermal analysis is performed on the internal combustion engines made of Grey Cast Iron material with a coating of TBC material on the inner side of the combustion chamber walls. The thickness of each coating is 1000 microns $(1 \mathrm{~mm})$.

\subsection{Thermal Analysis On Strontium ZirconateCoated Engine}

A well-established thermal barrier coating is Strontium Zirconate which has a higher thermal stability of up to $1573 \mathrm{~K}$. The Grey Cast Iron IC Engine is coated with Strontium Zirconate on its combustion chamber walls completely and thermal analysis is carried out as before. At the end of 30 seconds of thermal simulation over the strontium Zirconate coated IC Engine, the heat distribution is observed as shown in the figure 8. 


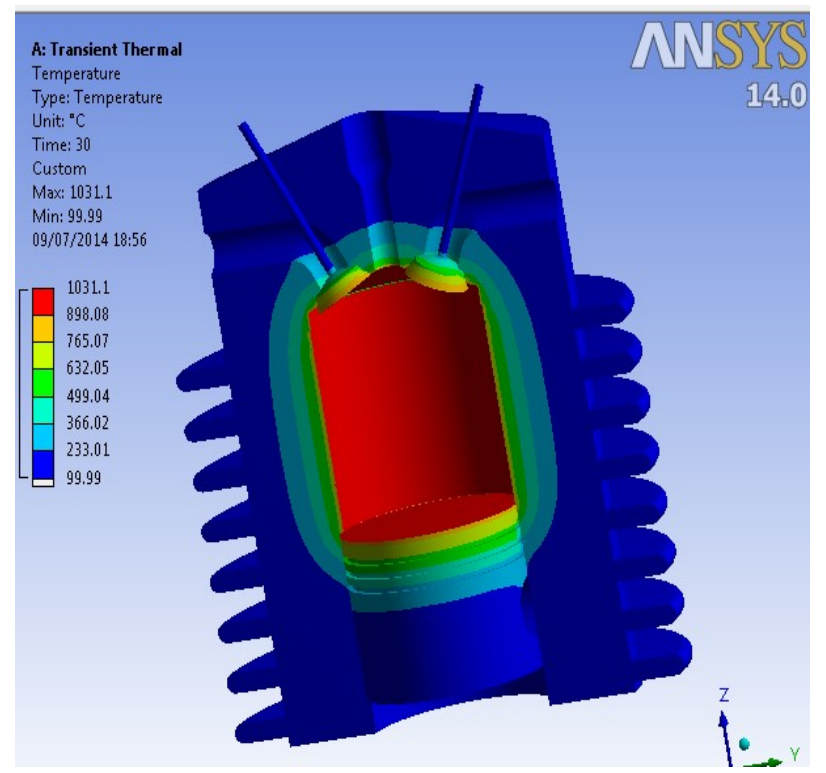

Figure 8. Temperature Distribution In An IC ENGINE Made Of GREY CAST IRON Coated Internally With STRONTIUM ZIRCONATE TBC

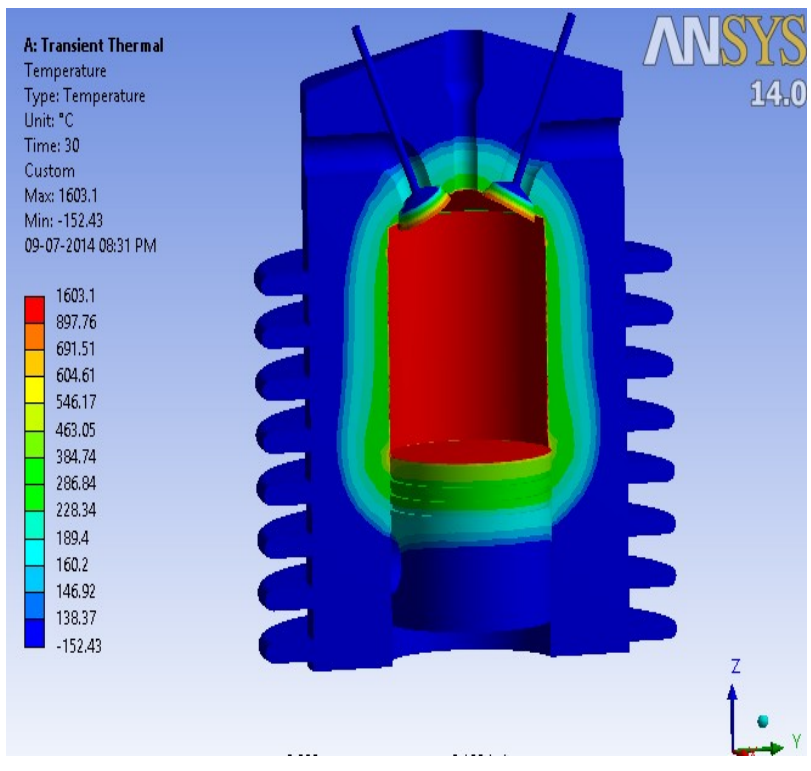

Figure 9. Temperature Distribution In An IC ENGINE Made Of GREY CAST IRON Coated Internally With BLT TBC

\subsection{Thermal Analysis On BLT CoAted Engine}

Barium Lanthanum Titanate (BLT) is relatively a new found thermal barrier coating material which has approximately $25 \%$ more thermal stability than Strontium Zirconate. It can resist phase transition up to $1773 \mathrm{~K}$ with thermal conductivity of $0.7 \mathrm{~W} / \mathrm{mK}$ which is an added advantage in terms of reliability of engine operation in the event of sudden surge in temperature during combustion. The conditions of thermal simulations are maintained the same. The temperature distribution is observed to be as shown in figure 9 .

\section{Results and Discussion}

At the end of 30 seconds simulation, the results of temperature distribution obtained for each of the five IC Engines discussed are as tabulated in table 3. We know, lower heat rejection from the combustion chamber through thermally insulated components causes an increase in available energy which in turn would increase the in-cylinder work and the amount of energy carried by the exhaust gases, which could also be utilized in later stages by using LHR (Low Heat Rejection) systems.

Table 3. Engine Body Temperatures of Various Engine Models (upon thermal analysis for 30 seconds)

\begin{tabular}{|l|c|c|c|c|}
\hline $\begin{array}{l}\text { TEMPERATURE AT VARIOUS } \\
\text { SECTIONS }\end{array}$ & $\begin{array}{c}\text { ALUMINIUMSIL } \\
\text { ICON ALLOY }\end{array}$ & $\begin{array}{c}\text { GCI(ASTM } \\
\text { GRADE 40) }\end{array}$ & $\begin{array}{c}\text { STRONTIUM } \\
\text { ZIRCONATE }\end{array}$ & \multirow{2}{\text{BLT}}{} \\
\hline $\begin{array}{l}\text { On the walls of Combustion } \\
\text { Chamher }\end{array}$ & $1173 \mathrm{~K}$ & $1173 \mathrm{~K}$ & $1173 \mathrm{~K}$ & $1173 \mathrm{~K}$ \\
\hline Liner Part & $1173 \mathrm{~K}$ & $1173 \mathrm{~K}$ & $1050 \mathrm{~K}$ & $750 \mathrm{~K}$ \\
\hline Cylinder Block & $1000-820 \mathrm{~K}$ & $1073-550 \mathrm{~K}$ & $950-500 \mathrm{~K}$ & $730-450 \mathrm{~K}$ \\
\hline Fins & $730 \mathrm{~K}$ & $373 \mathrm{~K}$ & $373 \mathrm{~K}$ & $373 \mathrm{~K}$ \\
\hline Piston Body & $1173-473 \mathrm{~K}$ & $1173-450 \mathrm{~K}$ & $1000-373 \mathrm{~K}$ & $730-373 \mathrm{~K}$ \\
\hline Valve Head & $1173 \mathrm{~K}$ & $1173 \mathrm{~K}$ & $\sim 1050 \mathrm{~K}$ & $\sim 750 \mathrm{~K}$ \\
\hline Overhead Block & $1173-820 \mathrm{~K}$ & $1173-373 \mathrm{~K}$ & $700 \mathrm{~K}-373 \mathrm{~K}$ & $700-373 \mathrm{~K}$ \\
\hline
\end{tabular}

In other words, the combustion process tends to be more adiabatic (isentropic) in nature which means we are making the cycle a better approximation to Otto Cycle. Hence, we can say that the use of Strontium Zirconate TBC will increase the thermal efficiency of the IC Engine and thereby the net work output during the cycle. When BLT TBC is used, the heat dissipated into the engine body is further reduced than in the case of Strontium Zirconate; making it the better of two proposed engine models using TBCs when it comes to improving its thermal efficiency. 


\section{Conclusion}

The 3D Finite Element Thermal Analysis is thus performed on five different models of IC Engines. Upon the thermal analysis, we can see that the use of TBCs greatly reduced the heat dissipation through engine body during combustion. The following inferences are made.

- The use of TBCs in IC Engines will definitely improve the thermal efficiency.

- Furthermore, BLT TBC is found to be the most viable TBC material for use in petrol (gasoline) based IC Engine, on account of its high thermal phase stability and low thermal conductivity.

- Smaller engine cooling system is sufficient.

- More intake charge may be expected in case of naturally aspirating engines which means higher volumetric efficiency as well.

- The liner would show lesser wear because of higher hardness of TBC materials.

\section{References}

[1] D.R. Clarke and S.R. Phillpot, Thermal Barrier Coating Materials, Mater. Today, 2005.

[2] Z. Mišković, I. Bobić, S. Tripković, A. Rac, A. Vencl, The Structure and Mechanical Properties of an Aluminium A356 Alloy Base Composite With Al2O3 Particle Additions, Tribology in industry, Volume 28, No. 3\&4, 2006.

[3] A.C. Alkidas, Performance and emissions achievements with an uncooled heavy duty, single cylinder diesel engine, SAE, vol. 890141, 1989.

[4] Xizhong Wang, Lei Guo, HongboGuo, Guohui Ma, Shengkai Gong, Effects of Pressure during Preparation on the Grain Orientation of Ruddlesden-Popper Structured BaLa2Ti3O10 Ceramic, Journal of Materials Science \& Technology 01/2013.

[5] Hieu Nguyen, Manufacturing Processes and Engineering Materials Used in Automotive Engine Blocks, April 8, 2005.

[6] Lei Guo, HongboGuo, Guohui Ma, Musharaf Abbas, Shengkai Gong, Ruddlesden-Popper structured BaLa2Ti3O10, a highly anisotropic material for thermal barrier coatings, $2012|38| \underline{5} \mid$ 4345-4352.

[7] Shinsuke Yamanaka, Ken Kurosaki, TakuOyama, Hiroaki Muta, Masayoshi Uno, Tetsushi Matsuda, Shin-Ichi Kobayashi, Thermophysical Properties of Perovskite-Type Strontium Cerate and Zirconate, Journal of the American Ceramic Society (Impact Factor: 2.11). 05/2005; 88(6):1496 - 1499. DOI:10.1111/j.1551-2916.2005.00278x.

[8] Y. Miyairi, Soc. Automot. Eng. 880187 (1989).

[9] A. Uzun, I. Cevik, M. Akcil, Effects of thermal barrier coating material on a turbocharged diesel engine performance, Surf. Coat. Technol. 116-119 (1999) 505

[10] T. Hejwowski, A. Weronski, The effect of thermal barrier coatings on diesel engine performance, Vacuum 65 (2002) 427.

[11] E. A. Slonimskaya, A. V. Belyakov, Ceramics Based on Strontium Zirconate (A Review), Glass and Ceramics (Impact Factor: 0.18). 12/2000; 58(1):54-56.

[12] K. Toyama, T. Yoshimitsu, T. Nishiyama, Heat insulated turbo compound engine, SAE Transactions, vol. 92, 1983, p. 3.1086. 